\title{
Diabetes mellitus and non-traumatic lower extremity amputations in four public sector hospitals in Cape Town, South Africa, during 2009 and 2010
}

\author{
G L Dunbar, ${ }^{1}$ BSc, MB ChB, FCFP (SA), MMed Fam Med, DA (SA); D A Hellenberg, ${ }^{1}$ MB ChB, MFamMed, FCFP (SA); \\ N S Levitt, ${ }^{2} \mathrm{MB}$ ChB, MD, FCP (SA) \\ ${ }^{1}$ Division of Family Medicine, Faculty of Health Sciences, University of Cape Town, South Africa \\ ${ }^{2}$ Division of Diabetic Medicine and Endocrinology, Groote Schuur Hospital and Faculty of Health Sciences, University of Cape Town, South Africa
}

Corresponding author: N S Levitt (naomi.levitt@uct.ac.za)

\begin{abstract}
Background. Diabetes mellitus (DM) is the most commonly reported cause of non-trauma-related lower extremity amputations (LEAs) worldwide, but there is a dearth of such information for South Africa (SA).

Objectives. To examine the proportion of LEAs due to diabetes and to describe the associated characteristics of these patients.

Methods. A retrospective analysis of all LEAs was performed in four public sector hospitals in Cape Town, SA, for 2009 and 2010. Operating theatre records were reviewed to identify all patients who had an LEA. Patient records were perused and information extracted using a structured questionnaire.

Results. Records for 941 of 1134 patients identified as having an LEA were found (recovery rate 82.9\%). Of the 867 patients with 1280 LEAs included in the study, 925 LEAs were in 593 patients with DM and 355 LEAs in 274 non-DM patients. Therefore $72.3 \%$ (95\% confidence interval (CI) 69.8 - 74.7) of LEAs were in people with DM, while 68.4\% (95\% CI 65.2 - 71.4) of the total patients had DM. The DM group underwent more multiple LEAs $(42.0 \%$ v. $23 \%$; $p<0.001)$ and had more multiple admissions $(14.3 \%$ v. $7.7 \%$; $p<0.005)$ than the non-DM group. Infection $(85.7 \%$ v. $63.5 \%$; $p<0.001)$ and ulcer $(25.3 \%$ v. $15.3 \% ; p=0.001)$ were the leading causes for LEA in the DM group compared with the non-DM group. Ischaemia was the dominant cause in the non-DM patients $(49.3 \% \mathrm{v} .23 .3 \%$; $p<0.001)$, as was smoking $(69.7 \% \mathrm{v}$. $43.5 \%, p<0.001)$, compared with the DM patients.

Conclusions. These data demonstrate an alarming burden of LEAs due to DM in the public sector in Cape Town. Given that the majority of LEAs are preventable with adequate education, screening, treatment and follow-up, effective interventions are needed.

S Afr Med J 2015;105(12):1053-1056. DOI:10.7196/SAMJ.2015.v105i12.9276
\end{abstract}

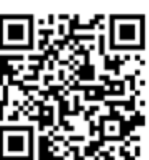

Diabetes mellitus (DM) is a major cause of morbidity and mortality globally. In 2010 an estimated 285 million adults had DM. This was projected to rise to 439 million adults by 2030; however, the most recent International Diabetes Federation estimates are that in 2014, 387 million people already had DM, and by 2035 this will rise to 592 million. The prevalence of DM continues to increase, with the largest increase seen in low- and middle-income countries; in South Africa (SA) the prevalence is also rising. ${ }^{[1-5]}$ This increase is mainly due to the growth and ageing of the population, as well as rising rates of urbanisation with associated increased levels of obesity, physical inactivity and unhealthy diet. ${ }^{[6-8]}$ This escalating number of people with DM will impact on disease management systems. DM accounted for $4.3 \%$ of all deaths in SA in 2000, placing it as the seventh most common cause of death in this country. ${ }^{[6]}$

The complications of DM are not only common but devastating, and include lower extremity amputations (LEAs), blindness and renal failure, with DM being the most common cause for non-traumarelated LEAs. There is a wide range in the proportion of LEAs due to DM, with studies showing that up to $90 \%$ of LEAs worldwide are associated with DM and up to $70 \%$ of patients who undergo an LEA die within 5 years of the operation. ${ }^{[6,9,10]}$

There are some African data on diabetes-related LEAs, primarily from small tertiary hospital studies. In each, diabetic foot complications were the major indication for non-traumatic LEAs. ${ }^{[1-13]}$ There are, however, few published data available for SA, and this study attempts to address this deficit, providing a baseline from which further monitoring and planning can be done.

The aim of this study was to examine the contribution of DM to the burden of LEAs in four public sector hospitals in Cape
Town, SA, during 2009 and 2010. The objectives were to determine the demographic characteristics of patients undergoing LEAs, the proportion of these amputations due to DM, the comorbidities, risk factors, causes and complications associated with these LEAs, and the number and sites of these LEAs.

\section{Methods}

The study was a retrospective analysis of all LEAs performed in four Cape Town public sector hospitals: Groote Schuur Hospital, a tertiary level hospital, and its associated secondary level hospitals, Somerset, Victoria and G F Jooste Hospitals, from 1 January 2009 to 31 December 2010. These are the public sector hospitals that perform LEAs in the western portion of the Cape Town metropole. Cape Town is situated in the Western Cape Province of SA and has a heterogeneous population of approximately 3.5 million people. Like the rest of SA, disease management is split between the public and private sectors, with $80 \%$ of the population being dependent on the public sector. ${ }^{[14,15]}$

All cases of LEAs, defined as the surgical removal of part of the lower limb by transection of the leg, foot or digit, necessarily including the removal of bone ${ }^{[16]}$ were identified from the theatre registers of these four hospitals for 2009 and 2010. All cases including the terms above-knee amputation (AKA), through-knee amputation (TKA), below-knee amputation (BKA), supramalleolar amputation (SMA), forefoot/transmetatarsal amputation (TMA) and digit amputation (DA) were included as an LEA in this study.

The identified patients' records were requested from the corresponding hospitals' records departments, and information was extracted using a structured data capture form. The data collected included number and length of admissions, demographic 
details, diabetic status, type and treatment, associated comorbidities, risk factors, cause, amputation details and complications.

Trauma-related LEAs were excluded. Of the non-trauma-related LEAs, patients whose diabetic status was unknown were also excluded.

Descriptive analysis included percentages for categorical data, means, medians, standard deviations and ranges for numerical data where appropriate. Tests of significance included the $\chi^{2}$, Fisher's exact and Wilcoxon tests. Statistical significance of $p<0.05$ was used.

The study was approved by the University of Cape Town Ethics Research Committee, HREC Ref: 365/2011. Permission to access patient records from the various hospitals was received.

\section{Results}

As seen in Fig. 1, records for 941 patients were found from the 1134 patients identified as having an LEA from theatre records, a recovery rate of $82.9 \%$. After exclusion of 39 patients who had a traumatic LEA and a further 35 with unknown DM status, a total of 867 patients with 1280 LEAs remained, 593 DM patients with 925 LEAs and 274 non-DM patients with 355 LEAs; $72.3 \%$ (95\% confidence interval (CI) 69.8 - 74.7) and $27.7 \%$ (95\% CI $25.4-30.3$ ) of the LEAs were therefore in DM and non-DM patients, respectively. Of the total number of patients, 68.4\% (95\% CI 65.2 - 71.4) had DM.

The mean age (standard deviation (SD)) of all included patients was $62.2(12.74)$ years. There was no significant difference in the mean age of men and women within and between the DM and non-DM groups. There were similar proportions of men and women in the DM group $(50.1 \%$ and $49.9 \%$, respectively), but twice as many men as women in the non-DM group $(66.8 \% \mathrm{v}$. $33.2 \%, p<0.001$ ). (The patient records no longer include a population classification code, so this information is not reported.)

Type 2 DM accounted for the majority of the patients in the DM group ( $n=551$, $92.9 \%) ; 7$ patients (1.2\%) had type $1 \mathrm{DM}$, while the type of diabetes was unknown in 35 (5.9\%). Regarding therapy, 299 (50.4\%) were on oral therapy, $104(17.5 \%)$ were on insulin, $128(21.6 \%)$ were on a combination of oral and insulin therapy, $3(0.5 \%)$ were on no therapy, $7(1.2 \%)$ were on diet alone and therapy in $52(8.8 \%)$ was unknown.

Table 1 summarises the comorbidities, risk factors, causes and complications associated with an LEA in the DM and non-DM groups.

Comorbidities. Hypertension, ischaemic heart disease (IHD) and renal impairment were significantly more common in the DM group than in the non-DM group $(p<0.001)$.

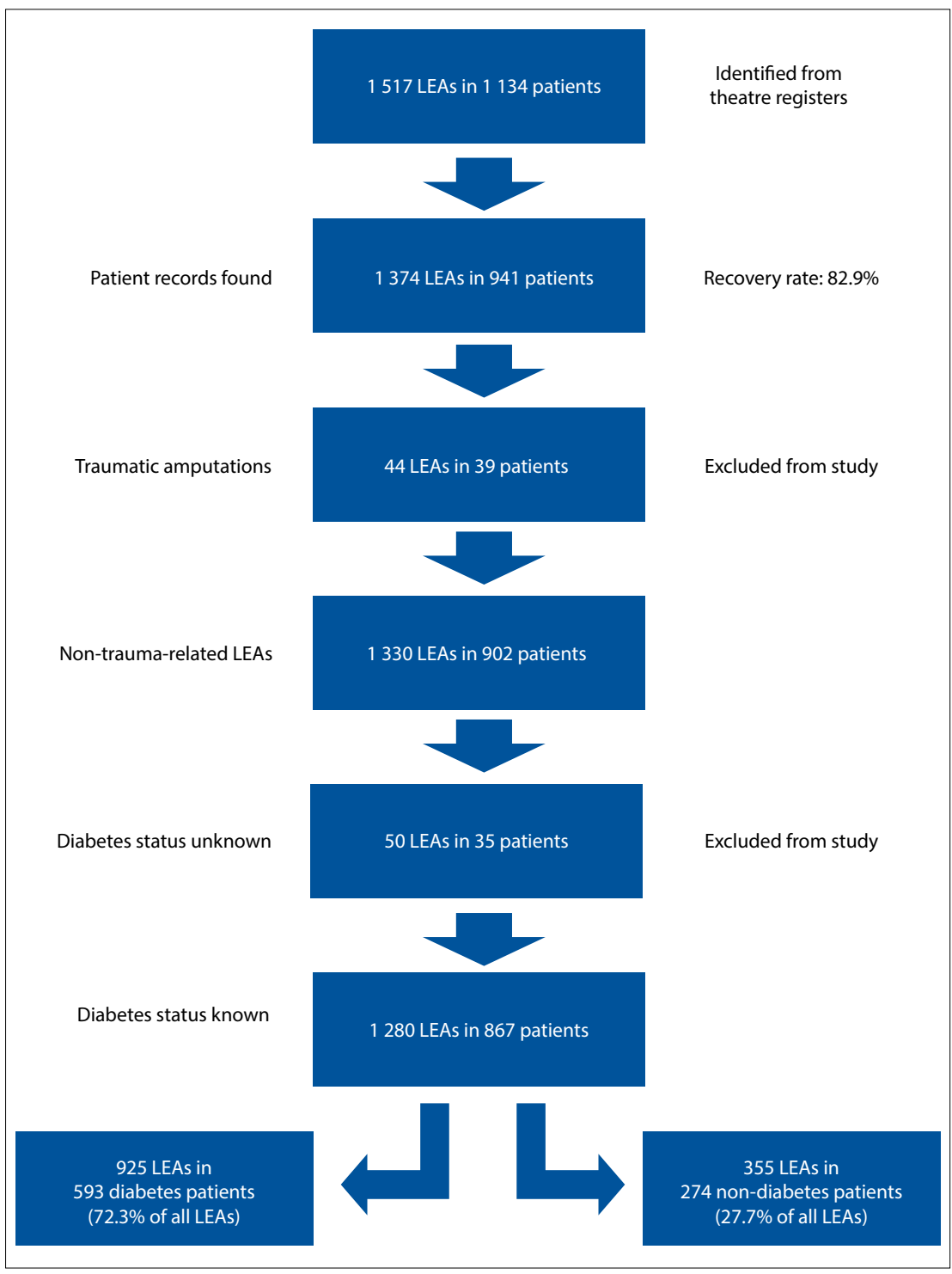

Fig. 1. Flow diagram for inclusion and exclusion of patients in the study.

Conversely, associated alcohol use, asthma/ chronic obstructive pulmonary disease (COPD) and HIV infection, were more common in the non-DM than the DM group $(p<0.001)$, but associated cerebral vascular accidents (CVAs)/transient ischaemic attacks (TIAs) and congestive cardiac failure frequencies did not differ in the DM and non-DM groups.

Associated risk factors. Smoking was the only associated risk factor that was significantly different between the two groups $(43.5 \%$ in the DM group and in $69.7 \%$ in the non-DM group; $p<0.001$ ).

Causes of the LEAs. Infection was the major cause of LEAs in both groups, albeit significantly higher in the DM group $(p<0.001)$. Ischaemia accounted for a significantly greater proportion of LEAs in the non-DM group $(p<0.001)$, whereas an ulcer was responsible for a significantly greater proportion of LEAs in the DM group $(p=0.001)$. Less common causes, including burns $(p<0.05)$, were more common in the
DM group, while malignancy $(p<0.01)$, limb deformity $(p<0.05)$, neurological disorder $(p<0.01)$ and HIV vasculopathy $(p<0.01)$ were more common in the nonDM group.

Complications associated with the LEAs. There were significant differences for the main complications between the two groups, with a further LEA, sepsis and debridement being more common in the DM group than the non-DM group $(p<0.05)$. There was no significant difference for the other main complications of in-hospital death, blood transfusion, and intensive care unit (ICU) admission, or regarding other complications of deep-vein thrombosis (DVT), upper gastrointestinal tract (GIT) bleed and pneumonia between the DM and non-DM groups, although these numbers were very small.

The median duration of hospital admission was 9 days, with an interquartile range of 7 days for both groups, and a range of $1-45$ 
days for the DM patients and 1 - 79 days for the non-DM patients. The 867 patients in the

study were admitted 988 times; there were 688 admissions in the $593 \mathrm{DM}$ patients and

Table 1. Comparison of comorbidities, risk factors, causes and complications between DM and non-DM patients having a lower extremity amputation

\begin{tabular}{|c|c|c|c|}
\hline & $\begin{array}{l}\text { DM group } \\
n(\%)\end{array}$ & $\begin{array}{l}\text { Non-DM group } \\
n(\%)\end{array}$ & $p$-value \\
\hline \multicolumn{4}{|l|}{ Comorbidities } \\
\hline Hypertension & $493(83.1)$ & $148(54.0)$ & $<0.001$ \\
\hline CVA/TIA & $76(12.8)$ & $40(14.6)$ & 0.4735 \\
\hline Ischaemic heart disease & $103(17.4)$ & $29(10.6)$ & 0.0097 \\
\hline Alcohol & $28(4.7)$ & $41(15.0)$ & $<0.001$ \\
\hline Asthma/COPD & $24(4.1)$ & $27(9.9)$ & $<0.001$ \\
\hline Congestive cardiac failure & $33(5.6)$ & $8(2.9)$ & 0.088 \\
\hline Renal impairment & $28(4.7)$ & $3(1.1)$ & 0.0074 \\
\hline HIV & $2(0.3)$ & $23(8.4)$ & $<0.001$ \\
\hline \multicolumn{4}{|l|}{ Risk factors } \\
\hline Hypercholesterolaemia & $75(12.7)$ & $27(9.9)$ & 0.2359 \\
\hline Smoking & $258(43.5)$ & $191(69.7)$ & $<0.001$ \\
\hline Peripheral vascular disease & $138(23.3)$ & $76(27.7)$ & 0.1563 \\
\hline Peripheral neuropathy & $13(2.2)$ & $3(1.1)$ & 0.2653 \\
\hline \multicolumn{4}{|l|}{ Causes } \\
\hline Ulcer & $150(25.3)$ & $42(15.3)$ & 0.001 \\
\hline Infection & $508(85.7)$ & $174(63.5)$ & $<0.001$ \\
\hline Ischaemia & $138(23.3)$ & $135(49.3)$ & $<0.001$ \\
\hline \multicolumn{4}{|l|}{ Complications } \\
\hline In-hospital death & $34(5.7)$ & $17(6.2)$ & 0.7841 \\
\hline Further amputation & $250(42.2)$ & $63(23.0)$ & $<0.001$ \\
\hline Blood transfusion & $65(11.0)$ & $24(8.8)$ & 0.3206 \\
\hline Diabetic ketoacidosis & $12(2.0)$ & & \\
\hline ICU admission & $10(1.7)$ & $5(1.8)$ & 0.5399 \\
\hline Sepsis/debridement & $52(8.8)$ & $13(4.7)$ & 0.0364 \\
\hline Other complications $s^{\star}$ total & $9(1.5)$ & $4(1.5)$ & 0.9781 \\
\hline
\end{tabular}

300 admissions in the 274 non-DM patients. Multiple admissions were more common in the DM patients $(14.3 \%)$ compared with the non-DM patients $(7.7 \%)(p<0.005)$.

The DM group had a greater proportion of current multiple LEAs than the nonDM group $(42 \%$ v. $23 \%, p<0.001)$, while $20.4 \%$ in the DM group and $17.2 \%$ in the non-DM group had an LEA prior to the commencement of the study.

As seen in Fig. 2, the proportions of multiple toectomies and TMAs did not differ significantly between the two groups. However, the proportions of single toectomies $(p=0.002)$, SMAs $(p<0.0001)$, and BKAs $(p<0.0001)$, were higher in the DM patients, while TKAs $(p<0.0001)$ and AKAs $(p<0.0001)$ were higher in the non-DM group.

\section{Discussion}

DM accounted for the vast majority of nontraumatic LEAs performed in 2009 and 2010 in four public sector hospitals in Cape Town. On average six (number rounded up from 5.7) DM patients had nine (number rounded up from 8.9) LEAs per week over the 2-year period.

These data highlight the considerable burden that diabetes-related LEAs impose on local health services. This is in keeping with numerous studies conducted elsewhere that have stated that LEAs represent a considerable cost for such services, not only for the admission and amputation, but also for the additional components of rehabilitation, home care and social services. ${ }^{[6,9,17,18]}$ The human cost is also considerable for the patients, their families and society. The best way to decrease these costs is to decrease the number of foot complications, including LEAs.

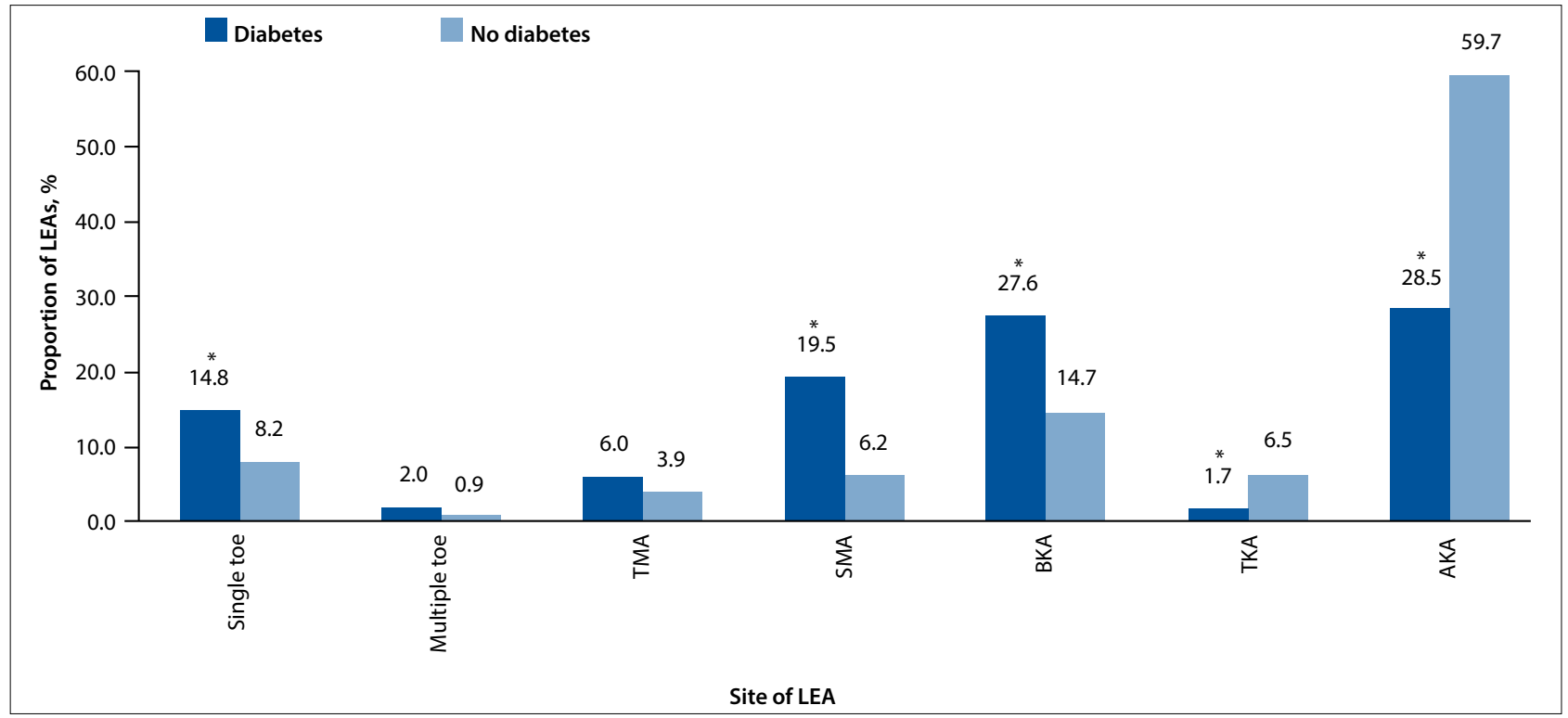

Fig. 2. Distribution (\%) of current LEAs by site in the DM and non-DM patients. ( ${ }^{*}$ Indicates significant differences $(\mathrm{p}<0.002)$ between DM and non-DM groups.) 
This study found that the associated comorbidities of hypertension, IHD and renal impairment were more common in the DM patients. This is similar to other studies and is thought to be due in part to the increasing westernisation of lifestyles. ${ }^{[3,19,20]}$ The associated renal impairment probably reflects complications of DM due to poor glycaemic control.

Smoking was the only associated risk factor found to be different, being more prevalent in non-DM patients. This was also reflected in the fact that associated asthma/COPD was more prevalent in the non-DM group. Yet a large proportion of DM patients (43\%) smoked, which is of concern, as smoking is known to increase the risk of LEAs in people with DM. ${ }^{[19]}$ Associated peripheral vascular disease (PVD) was similar between the DM and non-DM groups, with about $25 \%$ of patients noted to have PVD as a risk factor, which is similar to a previous study. ${ }^{[21]}$ This study found only a small number of patients with associated peripheral neuropathy in the DM group, yet peripheral neuropathy is known to be a substantial cause of foot complications including LEAs. ${ }^{[8,22]}$ The number of patients with associated peripheral neuropathy is probably artificially low, reflecting under-reporting in the patient records.

A preceding ulcer and infection were the more common causes for LEAs in the DM patients, which is in keeping with what previous studies have shown. ${ }^{[3,9,17,19,23]}$ Ischaemia was the most common cause for LEAs in the non-DM patients, perhaps reflecting the higher rate of smoking in this group. Burns causing LEAs were more common in the DM group and can probably be attributed to associated peripheral neuropathy. Under-reporting of peripheral neuropathy probably reflects failure on the part of healthcare workers to screen for this complication. They are therefore not educating patients on the danger of infections, burns, etc.

Post-LEA sepsis and debridements were found to be more common in the DM patients. This was expected, as sepsis was often the cause for the LEA in this group. Nearly 20\% of LEAs in DM patients were SMAs. This indicates that sepsis was a major cause, as this operation is usually a sepsis control procedure, the definitive procedure being a BKA or AKA. It is also notable that the percentage of AKAs in the non-DM group was double that in the DM group. This may be because DM patients have more LEAs due to an ulcer or infection, requiring a more distal amputation, whereas nonDM patients have more LEAs due to ischaemia, requiring a more proximal amputation. The greater proportion of current, multiple LEAs in the DM group compared with the non-DM group reflects the fact that 'creeping' LEAs, i.e. multiple LEAs that start distally and progress proximally, are more prevalent in the DM group.

The strengths of this study are the large numbers of patients identified with a good recovery rate, as well as similar methodology employed as in other global studies. ${ }^{[2]}$ However, it has a number of limitations. Its retrospective nature allowed only for information recorded in the patient folders to be evaluated. Accurate data for comorbidities, risk factors, causes and complications associated with a LEA would require a prospective study. The records often revealed limited information on other factors such as the level of glycaemic control, duration of DM and obesity. The study was undertaken only in the public sector, thus underestimating the true burden of diabetes-related LEAs. Because of the lack of accurate data on DM incidence and population size in the study area, it is difficult to extrapolate the number of LEAs identified in this study to the prevalence of diabetes-related LEAs.

It is well known that the majority of foot complications, including LEAs, are preventable with adequate patient education, screening, treatment and follow-up. ${ }^{[3,16,23,25,26]}$ In this regard we have previously demonstrated that a third of patients attending primary care clinics in Cape Town had 'at-risk feet' although this had often been unrecorded in the clinic notes. ${ }^{[27]}$ A number of reasons may account for suboptimal foot care: high patient numbers and decreased consultation times leading to infrequent foot examinations, limited opportunities for patient education and therefore non-adherence, as well as inadequate overall treatment at a primary healthcare level..$^{[6,19,28]}$ While preventive diabetes foot care is not the sole preserve of the doctor or a podiatrist, it is important to note that there is a lack of podiatrists to adequately prevent and treat these complications. Nurses, health promoters and community health workers can all contribute to a diabetes foot programme, but would need to receive appropriate training to enable patients to be active participants in their own care, to screen for at-risk feet and to refer appropriately for further management.

\section{Conclusions}

This study highlights the enormous burden of LEAs in the public sector. There is clearly an urgent need to develop and implement foot care programmes to reduce the personal, societal and disease management costs associated with LEAs. This study provides a baseline against which the effectiveness of interventions can be measured in the future.

\section{References}

1. Shaw JE, Sicree RA, Zimmet PZ. Global estimates of the prevalence of diabetes for 2010 and 2030 Diabetes Res Clin Pract 2010;87(1):4-14. [http://dx.doi.org/10.1016/j.diabres.2009.10.007]

2. Peer N, Steyn K, Lombard C, Lambert EV, Vythilingum B, Levitt N. Rising diabetes prevalence amon urban-dwelling black South Africans. PLoS One 2012; 4 Sept. [http://dx.doi.org/10.1371/journal. pone.0043336]

3. International Diabetes Federation. IDF Diabetes Atlas. http://www.diabetesatlas.org/ (accessed October 2015).

Bertram MY, Jaswal AVS, Pillay van Wyk V, Levitt NS, Hofman KJ. The non-fatal disease burden caused by type 2 diabetes in South Africa, 2009. Global Health Action 2013;6:19244. [http://dx.doi. org/10.3402/gha.v6i0.19244

5. Mayosi BM, Flisher AJ, Lalloo UG, Sitas F, Tollman SM, Bradshaw D. The burden of noncommunicable diseases in South Africa. Lancet 2009;374(9693):934-947. [http://dx.doi.org/10.1016/ S0140-6736(09)61087-4]

6. Bradshaw D, Norman R, Pieterse D, Levitt NS and the South African Comparative Risk Assessment Group. Estimating the burden of disease attributable to diabetes in South Africa in 2000. S Afr Med J 2007:97(8):700-706.

Mbanya JCN, Motala AA, Sobngwi E, Assah FK, Enoru ST. Diabetes in sub-Saharan Africa. Lancet 2010;375(9733):2254-2266. [http://dx.doi.org/10.1016/S0140-6736(10)60550-8]

8. Gill GV, Mbanya JC, Ramaiya KL, Tesfaye S. A sub-Saharan African perspective of diabetes. Diabetologia 2009;52(1):8-16. [http://dx.doi.org/10.1007/s00125-008-1167-9]

9. Boulton AJM, Vileikyte L, Ragnarson-Tennvall G, Apelqvist J. The global burden of diabetic foo disease. Lancet 2005;366(9498):1719-1724. [http://dx.doi.org/10.1016/S0140-6736(05)67698-2]

10. Girach A, Vignati L. Diabetic microvascular complications - can the presence of one predict the development of another? J Diabetes Complications 2006;20(4):228-237. [http://dx.doi.org/10.1016/j. jdiacomp.2006.03.001]

1. Chalya PL, Mabula JB, Dass RM, et al. Major limb amputations: A tertiary hospital experience in Northwestern Tanzania. J Orthop Surg Res 2012:7:18. [http://dx doi org/10.1186/1749-799X-7-18]

weluzo GO, Giwa SO, Adekoya-Cole TO, et al. Profile or hospital, Lagos, Nigeria. Nig Q J Hosp Med 2010;20(4):205-208.

13. Sié Essoh JB, Kodo M, Djè Bi Djè V, Lambin Y. Limb amputations in adults in an Ivorian teachin hospital. Niger J Clin Pract 2009;12(3):245-247.

14. Statistics South Africa. Community Survey 2007. https://www.statssa.gov.za/publications/P0301/ P0301.pdf (accessed 1 October 2015)

15. Health Systems Trust. Public Sector Dependent Population. http://indicators.hst.org.za/healthstats/14 data (accessed 1 October 2015).

6. Jeffcoate WJ, van Houtum WH. Amputation as a marker of the quality of foot care in diabetes. Diabetologia 2004;47(12):2051-2058. [http://dx.doi.org/10.1007/s00125-004-1584-3]

17. Clarke A. Avoiding foot complications in diabetes. CME 2010;28(4):181-185.

8. Apelqvist J, Larsson J. What is the most effective way to reduce incidence of amputation in the diabetic foot. Diabetes Metab Res Rev 2000;16(Suppl 1):75-83. [http://dx.doi.org/10.1002/15207560(200009/10)16:1+<::AID-DMRR139>3.0.CO;2-8]

19. Gamba MA, Gotlieb SLD, Bergmaschi DP, Vianna LAC Lower extremity amputations in diabetic patients: A case-control study. Rev Saude Publica 2004;38(3):1-5.

20. Levitt NS. Diabetes in Africa: Epidemiology, management and healthcare challenges. Heart 2008;94(11):1376-1382. [http://dx.doi.org/10.1136/hrt.2008.147306]

21. Johannesson A, Larsson G-U, Ramstrand N, Turkiewicz A, Wirehn A-B, Atroshi I. Incidence of lowerlimb amputation in the diabetic and nondiabetic general population. Diabetes Care 2009;32(2):275limb amputation in the diabetic and nondial

22. Solomon Tesfaye S, Gill G. Chronic diabetes complications in Africa. Africa Health 2011;33(3):37-40. http://www.africa-health.com/articles/may_2011/Diabetes.pdf (accessed 1 October 2015)

23. Tudhope L. The diabetic foot: Recognition and principles of management. CME 2009;27(7):312-315.

24. Unwin $\mathrm{N}$ and the LEA study group. Comparing the incidence of lower extremity amputations acros the world: The global lower extremity amputation study. Diabet Med 1995;12(1):14-18. [http://dx.do org/10.1111/j.1464-5491.1995.tb02055.x]

25. Distiller LA, Brown MA, Joffe BI, Kramer BD. Striving for the impossible dream: A community-based multi-practice collaborative model of diabetes management. Diabet Med 2010;27(2):197-202. [http:// dx.doi.org/10.1111/j.1464-5491.2009.02907.x]

26. Janse van Rensburg G. Preventative foot care in people with diabetes: Quality patient education. Journal of Endocrinology, Metabolism and Diabetes of South Africa 2009;14(2):1-2. [http://dx.doi.or J/10.1080/22201009.2009, Metabolis

27. Levitt NS, Bradshaw D, Zwarenstein MF, Bawa AA, Maphumolo S. Audit of public sector primary diabetes care in Cape Town, South Africa: High prevalence of complications, uncontrolled hyperglycaemia, and hypertension. Diabet Med 1997;14(12):1073-1077. [http://dx.doi.org/10.1002/ (SICI) 1096-9136(199712)14:12<1073::AID-DIA498>3.0.CO;2-9]

28. Steyn K, Levitt NS, Patel M, et al. Hypertension and diabetes: Poor care for patients at community health centres. S Afr Med J 2008;98(8):618-620

Accepted 5 October 2015. 